\title{
Naturally Occurring Fluctuation in Dendritic Spine Density on Adult Hippocampal Pyramidal Neurons
}

\author{
Catherine S. Woolley, Elizabeth Gould, Maya Frankfurt, and Bruce S. McEwen \\ Laboratory of Neuroendocrinology, Rockefeller University, New York, New York 10021
}

\begin{abstract}
We have used Golgi-impregnated tissue to demonstrate that apical dendritic spine density in CA1 hippocampal pyramidal cells undergoes a cyclic fluctuation as estradiol and progesterone levels vary across the estrous cycle in the adult female rat. We observed a $30 \%$ decrease in apical dendritic spine density over the 24-hr period between the late proestrus and the late estrus phases of the cycle. Spine density then appears to cycle back to proestrus values over a period of several days. In contrast, no significant changes in dendritic spine density across the estrous cycle occur in CA3 pyramidal cells or dentate gyrus granule cells. These results demonstrate rapid and ongoing dendritic plasticity in a specific population of hippocampal neurons in experimentally unmanipulated animals.
\end{abstract}

Steroid-mediated structural plasticity in the adult CNS has been demonstrated in sexually dimorphic systems such as the avian song-control nuclei (DeVoogd and Nottebohm, 1981) and the mammalian spinal nucleus of the bulbocavernosus (SNB; Kurz ct al., 1986, Forger and Breedlove, 1987; Sakasi and Arnold, 1989) using techniques of endocrine ablation and hormone replacement. In addition, Forger and Breedlove (1987) have shown seasonal variation in the morphology of SNB neurons in seasonally breeding mice. No previous studies, however, have addressed the possibility that plasticity in adult dendritic morphology occurs naturally as the consequence of normal, shortterm variation in the levels of steroid hormones.

The adult mammalian hippocampal formation appears to be a site of considerable plasticity, as both physiological (Bliss and Lomo, 1973; Diamond et al., 1989) and morphological (Steward, 1986; Desmond and Levy, 1988; Gould et al., 1990) changes have been observed in neurons of this brain region in response to a variety of experimental manipulations. This plasticity is particularly intriguing in that the hippocampus has been shown to be involved in cognitive processes such as learning and memory (Olton, 1983; Squire, 1983), which undoubtedly stem from changes at the cellular level. Insofar as neuronal structure has been shown to influence neuronal physiology (Lux et al., 1970; Enoka and Stuart, 1984; Kawato et al., 1984), it seems highly likely that morphological changes observed in the hippocampus have physiological and, ultimately, functional consequences. Our studies have been aimed at understanding the structural mech-

Received Apr. 17, 1990; revised Aug. 16, 1990; accepted Aug. 17, 1990.

This research was supported by Grant NS 07080 and The Richard Lounsbery Foundation.

Correspondence should be addressed to Catherine S. Woolley, Box 290, Laboratory of Neuroendocrinology, 1230 York Avenue, New York, NY 10021.

Copyright (C) 1990 Society for Neuroscience 0270-6474/90/124035-05\$03.00/0 anisms that may underlie hippocampal function in the normal adult brain by identification of the endogenous factors that mediate naturally occurring, as opposed to experimentally induced, neuronal plasticity.

Gonadal steroids have been shown to mediate some aspects of morphological plasticity in the adult hippocampus, as our laboratory has recently demonstrated that short-term ovariectomy results in a dramatic decrease in dendritic spine density in CA1 hippocampal pyramidal cells in the female rat (Gould et al., 1990). Estradiol treatment prevents this decrease; progesterone treatment augments the effect of estradiol.

Because hippocampal physiology in the female rat is known to vary as estradiol and progesterone levels fluctuate across the estrous cycle (Terasawa and Timiras, 1968; Kawakami et al., 1970), and because our previous results have indicated very short-term (5 hr; Gould et al., 1990) in vivo morphological sensitivity of hippocampal neurons to variations in ovarian steroid levels, the present study was undertaken in order to determine whether dendritic spine density fluctuates naturally during the 5 -d estrous cycle in the female rat. We have used Golgi-impregnated tissue to examine the density of dendritic spines on 2 portions of the dendritic tree in 3 hippocampal neuronal populations, CA 1 pyramidal cells, CA 3 pyramidal cells, and granule cells of the dentate gyrus, during the diestrus, proestrus, and estrus phases of the estrous cycle.

\section{Materials and Methods}

Experimental animals and treatments. Daily vaginal smears were taken from 24 virgin female Sprague-Dawley rats (110 d old, 250-275 gm) for 3 consecutive estrous cycles, and only those with normal 5-d cycles were used in this study. In the late afternoon of either the diestrus II ( $n$ $=7)$, proestrus $(n=8)$, or estrus $(n=8)$ phase of their cycle (Turner and Bagnara, 1976), these rats were deeply anesthetized with Ketalar (ketamine $\mathrm{HCl}$ ) and transcardially perfused with $100-150 \mathrm{ml} 4.0 \%$ paraformaldehyde in $0.1 \mathrm{M}$ phosphate buffer with $1.5 \%(\mathrm{v} / \mathrm{v})$ picric acid. Brains were postfixed in this solution overnight.

Histology. Following postfixation, brains were processed according to a modified version of the single-section Golgi impregnation procedure (Gabbott and Somogyi, 1984). Briefly, 100- $\mu$ m-thick coronal sections were cut into a bath of $3.0 \%$ potassium dichromate in distilled water using a vibratome. Sections were then incubated overnight in this solution. Following this, sections were rinsed in distilled water and mounted onto ungelatinized glass slides, and a coverslip was glued over the sections at the 4 corners. These slide assemblies were then incubated overnight in the dark in $1.5 \%$ silver nitrate in distilled water. Slide asscmblics werc then dismantled, and the sections were briefly rinsed in distilled water, dehydrated, cleared, and coverslipped.

Data analysis. Slides containing Golgi-impregnated brain sections were coded prior to quantitative analysis; the code was broken only after analysis was complete. Two measurements of dendritic spine density and a measurement of cross-sectional cell-body area were made from each selected Golgi-impregnated CA1 pyramidal cell, CA3 pyramidal cell, or dentate gyrus granule cell. In addition, a measurement of 
Table 1. Dendritic spine density during the estrous cycle

\begin{tabular}{|c|c|c|c|}
\hline Neural region & $\begin{array}{l}\text { Diestrus } \\
\text { (spines } / 10 \mu \mathrm{m} \text { ) }\end{array}$ & $\begin{array}{l}\text { Proestrus } \\
\text { (spines } / 10 \mu \mathrm{m} \text { ) }\end{array}$ & $\begin{array}{l}\text { Estrus } \\
\text { (spines } / 10 \mu \mathrm{m} \text { ) }\end{array}$ \\
\hline CA1 pyramidal cell apical dendrites (stratum lacunosum moleculare) & $10.5 \pm 1.0$ & $12.0 \pm 0.7$ & $8.4 \pm 0.5^{*}$ \\
\hline CA1 pyramidal cell basal dendrites (stratum oriens) & $7.6 \pm 0.5$ & $8.2 \pm 0.5$ & $6.7 \pm 0.4$ \\
\hline CA3 pyramidal cell apical dendrites (stratum lacunosum moleculare) & $11.3 \pm 1.4$ & $9.3 \pm 0.8$ & $8.9 \pm 0.8$ \\
\hline CA3 pyramidal cell basal dendrites (stratum oriens) & $6.1 \pm 0.7$ & $8.0 \pm 0.7$ & $6.9 \pm 0.4$ \\
\hline Granule cell proximal dendrites (inner molecular layer) & $8.1 \pm 1.0$ & $8.8 \pm 1.1$ & $7.0 \pm 0.4$ \\
\hline Granule cell distal dendrites (outer molecular layer) & $9.5 \pm 1.2$ & $10.3 \pm 0.9$ & $9.3 \pm 0.3$ \\
\hline
\end{tabular}

Values represent mean \pm SEM. Data were analyzed with a 1-way ANOVA with post hoc comparisons made with the Tukey HSD test.

* Significant difference from proestrus, $p<0.01$. All other comparisons were not significant.

the density of dendritic spines with heads compared to the density of total dendritic spines (with and without heads) on CA1 pyramidal cells was made.

In order to be selected for analysis, Golgi-impregnated neurons had to be (1) located within the appropriate subregion of the dorsal hippocampal formation, (2) thoroughly and consistently impregnated, and (3) easily discernible from neighboring impregnated cells.

From CA1 and CA3 pyramidal cells, one measurement of spine density was made from the lateralmost tertiary dendrite on the apical tree (located in the stratum lacunosum moleculare), and one was made from the lateralmost secondary dendrite on the basal tree (located in the stratum oriens). For dentate gyrus granule cells, one measurement was made from a secondary dendrite proximal to the cell body (located in the inner molecular layer), and one was made from the distal end of the longest dendrite (located in the outer molecular layer). In each case, spine density measurements were made as follows: From a selected dendrite, an appropriate segment, greater than $10 \mu \mathrm{m}$ in length, remaining in 1 plane of focus was traced $(1250 \times)$ using a camera lucida drawing tube. The number of dendritic spines (either all dendritic spines or only those with heads) visible along the segment was then counted, and the exact length of the segment was determined using the SMI (Southern Micro Instruments Inc.) morphometry program. Spine density was expressed as the number of spines per $10-\mu \mathrm{m}$ dendrite. As no attempt was made to correct for spines hidden beneath or above the dendrite of a selected segment, the dendritic spine density values obtained in this way likely underestimate the actual density of dendritic spines.

In addition to spine density measurements, a measurement of crosssectional cell-body area was made from each selected neuron. Cell bodies were traced $(1250 \times)$ using a camera lucida drawing tube, and the cellbody area was determined using the SMI morphometry program.

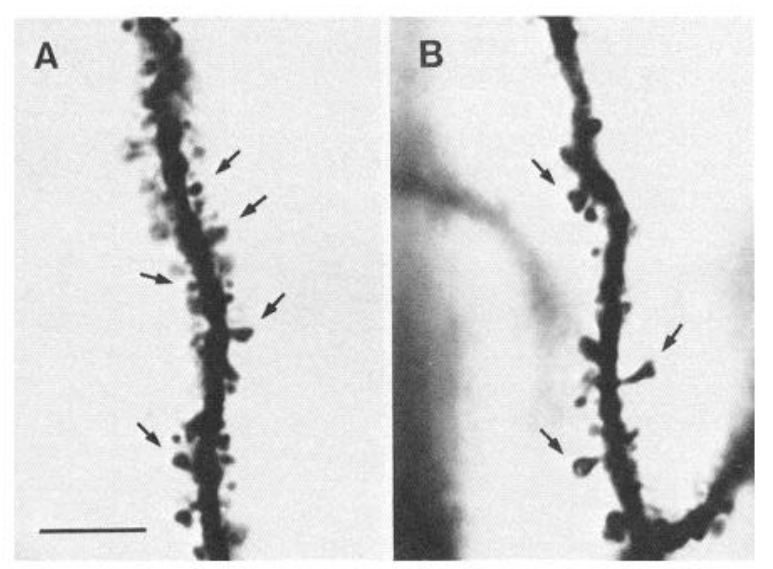

Figure 1. Photomicrographs of Golgi-impregnated apical dendrites from CA1 pyramidal cells of animal in proestrus $(A)$ or estrus $(B)$ phase of estrous cycle. The arrows indicate dendritic spines. Note the greater density of dendritic spines in $A$ compared to $B$. Scale bar, $10 \mu \mathrm{m}$ for both $A$ and $B$.
All measurements were made from different cells within the same brains by 2 investigators, and the data were combined to generate final values. For each animal, no fewer than 32 dendritic segments were analyzed: 16 from CA1 pyramidal cells, 8-16 from CA 3 pyramidal cells, and 8 from dentate gyrus granule cells. The means of each variable were determined for each animal and the data were analyzed using a 1-way analysis of variance (ANOVA), followed by Tukey HSD post hoc comparisons.

\section{Results}

Qualitative examination of Golgi-impregnated brain sections revealed consistent impregnation of adequate numbers of CA1 pyramidal cells, CA3 pyramidal cells, and dentate gyrus granule cells that met our selection criteria in the hippocampal formation of all animals used for this study.

Quantitative analysis of Golgi-impregnated dendrites from CA1 pyramidal cells revealed significant differences in apical dendritic spine density during the estrous cycle $(F[2,20]=6.1$, $p<0.01$; Figs. 1, 2). Rats in the estrus phase of the estrous cycle had significantly lower apical dendritic spine density than rats in the proestrus phase ( $p<0.01$; Fig. 3, Table 1). Although no significant differences were observed in dendritic spine density on the basal tree of CAl pyramidal cells $(F[2,20]=2.7, p$ $<0.1$ ), a trend toward a decrease was evident in basal dendritic spine density in rats in the estrus phase of the estrous cycle compared to rats in the proestrus phase $(p<0.1$; Table 1). Additionally, no estrous-cycle differences in the ratio of the density of dendritic spines with visible heads to total dendritic spines were detected in CA1 apical or basal dendrites.

In contrast to dendritic spine density in CA1 pyramidal cells, no significant differences or trends toward differences during the estrous cycle were observed in either apical or basal dendritic spine density in CA3 pyramidal cells ( $p>0.1$; Table 1$)$. Similarly, no significant differences were observed in either proximal or distal dendritic spine density in dentate gyrus granule cells ( $p>0.1$; Table 1). Furthermore, the cross-sectional cell-body area of CA1 pyramidal cells, CA3 pyramidal cells, and dentate gyrus granule cells was unchanged in any of the groups in this study ( $p>0.1$ for all comparisons; Table 2).

\section{Discussion}

These results demonstrate naturally occurring structural plasticity in a specific population of neurons in the adult mammalian hippocampal formation. In the female rat, apical dendritic spine density on CA1 pyramidal cells fluctuates during the 5-d estrous cycle. While such changes could conceivably be due to variation in the levels of either ovarian steroids or pituitary hormones, the results of our previous study, which employed ovariectomy 

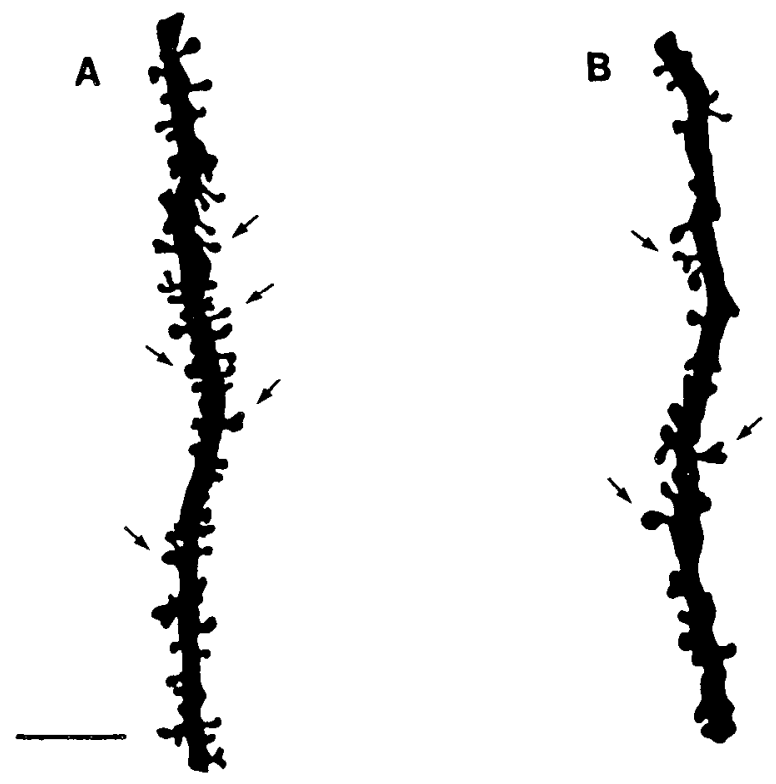

Figure 2. Camera lucida drawings of apical dendrites partially depicted in Figure 1. The arrows indicate the same dendritic spines indicated in Figure 1. Scale bar, $10 \mu \mathrm{m}$ for both $A$ and $B$.

and hormone replacement to demonstrate the dependence of spine density in the same neuronal population on estradiol and progesterone (Gould et al., 1990), indicate that the differences observed here are the result of differences in the levels of ovarian steroids.

The pattern of dendritic spine density fluctuation we have observed correlates very well with the changing levels of estradiol and progesterone during the cstrous cycle (Smith et al., 1975). During proestrus, when steroid levels are highest, spine density values are the greatest. During estrus, when estradiol and progesterone are at their lowest levels, spine density is also lowest. Intermediate estradiol levels during diestrus correlate with the intermediate spine density values we have observed for this phase of the estrous cycle. These results demonstrate that dendritic spines are remarkably plastic in that dendritic spine density decreases by over $30 \%$ during approximately 24 $\mathrm{hr}$ between the late afternoon of proestrus and late afternoon of estrus (Smith et al., 1975). Dendritic spine density then appears to cycle back from low values during estrus to high values during proestrus within a period of several days. Because the ratio of dendritic spines with visible spine heads to total dendritic spines does not change during the estrous cycle, it appears that neither population of spines (those with or without heads) is specifically lost or retained as total spine density fluctuates.

A comparison of the results presented here with those of our previous study (Gould et al., 1990) reveals that, both in the case

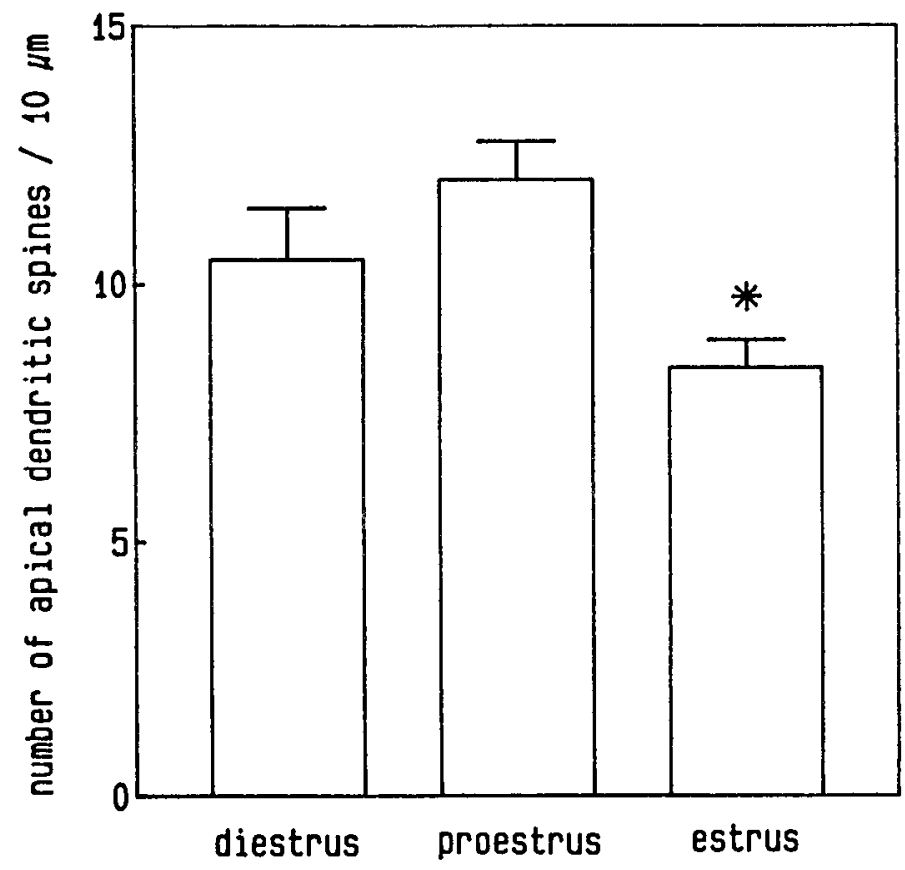

Figure 3. Number of dendritic spines per $10-\mu \mathrm{m}$ dendrite obtained from apical portion of CAl pyramidal cell dendritic tree. Values represent means + SEM. The asterisk denotes a significant difference from proestrus $(p<0.01)$.

of experimental manipulation and in natural variation of estradiol and progesterone levels, differences in dendritic spine density are detected only in CA1 pyramidal cells and not in CA3 pyramidal cells or dentate gyrus granule cells. Thus, within the hippocampal formation, thesc changes appcar to be specific to CA1 pyramidal cells.

Loy et al. (1988) have reported that pyramidal cells of the $\mathrm{CA} 1$ region accumulate estradiol, while very few $\mathrm{CA} 3$ pyramidal cells and no dentate gyrus granule cells were observed to do so. In addition, estrogen-inducible progesterone receptors have been reported in the CA1 region of the hippocampus (Parsons et al., 1982). These findings indicate that modulation of dendritic spine density may be a direct effect of estradiol and/or progesterone on CA1 pyramidal cells.

It is clear, however, that the CA1 apical and basal dendrites are differentially sensitive to variations in the levels of ovarian steroids, because a significant difference in dendritic spine density across the estrous cycle was detected only in the apical tree. If ovarian steroids are acting directly on CA1 pyramidal cells, such a result could be due to an inherent difference in apical and basal dendrites' morphologic plasticity such that apical dendritic spine density is more sensitive to variation in the levels of estradiol and/or progesterone. Alternatively, dendritic spine

Table 2. Cross-sectional cell-body area during the estrous cycle

\begin{tabular}{llll} 
Neuron type & Diestrus $\left(\mu \mathrm{m}^{2}\right)$ & Proestrus $\left(\mu \mathrm{m}^{2}\right)$ & Estrus $\left(\mu \mathrm{m}^{2}\right)$ \\
\hline CA1 pyramidal cell & $237.5 \pm 4.8$ & $231.7 \pm 5.5$ & $246.0 \pm 5.9$ \\
CA3 pyramidal cell & $425.4 \pm 11.5$ & $420.8 \pm 12.9$ & $454.3 \pm 26.3$ \\
Granule cell & $182.7 \pm 4.4$ & $170.8 \pm 6.2$ & $187.0 \pm 8.6$
\end{tabular}

Values represent mean \pm SEM. Data were analyzed with a 1-way ANOVA with post hoc comparisons made with the Tukey HSD test. No significant differences were observed. 
density could be modulated indirectly by an as yet unidentified steroid-sensitive factor to which CA1 pyramidal cell apical dendrites are more responsive, for example, an estradiol-sensitive afferent population that projects more densely to the apical than basal dendrites. These possibilities remain to be tested.

Changes in dendritic spine density during the estrous cycle are likely to have consequences for hippocampal neuronal function. Dendritic spines are specialized postsynaptic structures that, in part, determine the electrical properties of the dendrite on which they are located (Kawato et al., 1984; Wilson, 1984; Coss and Perkel, 1985). These spines are very often, if not always, occupied by synapses and are sites of excitatory input to CA1 pyramidal neurons (Westrum and Blackstad, 1962; Harris and Stevens, 1989). Thus, the changes we have observed strongly suggest that ovarian steroids regulate fluctuation in number and/or organization of excitatory synapses and thereby may modulate the excitatory input to CAl pyramidal neurons. Preliminary electron microscopic evidence from our laboratory supports this possibility; estradiol regulates synapse density in the stratum lacunosum moleculare of the CAl region (Woolley and McEwen, 1990). We are currently investigating whether similar changes in dendritic spine density across the estrous cycle also reflect natural fluctuation of synaptic density. It is intcresting to note that studies examining the effects of ovarian steroids on hippocampal neuronal excitability in vivo have correlated high levels of estradiol and progesterone with increased neuronal activity (Terasawa and Timiras, 1968; Kawakami et al., 1970). If increased derdritic spine density does reflect increased excitatory input, which could, in turn, increase neuronal activity, then our results present a possible structural mechanism to explain the effects of ovarian steroids on hippocampal neuronal excitability.

Previous studies have indicated that dendritic spines are remarkably plastic structures that can respond morphologically to a variety of physiological stimuli. Very rapid (on the order of minutes) alterations in the morphology of dendritic spines have been observed with behavioral manipulations in the honeybee (Brandon and Coss, 1982) and the jewel fish (Burgess and Coss, 1983). In the developing chick brain, visual experience results in changes in dendritic spines that correlate with increased neuronal excitability in the same brain region (Bradley and Horn, 1979; Brown and Horn, 1979). Several investigators have found that, in the hippocampal formation, electrical stimulation of afferent pathways modulates dendritic spine morphology and correlates with long-lasting changes in neuronal physiology (Fifkova and Van Harrelveld, 1977; Desmond and Levy, 1983; Chang and Greenough, 1984). These studies, which have associated changes in dendritic spines with experience and/ or altered neuronal physiology, have led to the suggestion that dendritic spines are a site of plasticity that could be involved in processes of learning and memory (Diamond et al., 1970; Brandon and Coss, 1982; Crick, 1982; Greenough, 1984, 1985; Seikevitz, 1985).

Our results demonstrate that hippocampal CAl pyramidal cell dendritic spine density, which we have previously shown to be dependent on ovarian steroid levels, fluctuates in a pattern that correlates very well with the changing levels of these hormones during the estrous cycle in the adult female rat. Because we have observed such structural changes over a short period (hours to days), it seems possible that longer-term differences in the levels of these same hormones, which occur during development, puberty, pregnancy, and senescence, result in an even greater degree of morphologic variation. Interestingly, ongoing morphologic plasticity has been observed in dendrites in the PNS (Purves et al., 1986), and, specifically within the CA1 hippocampal pyramidal cell population, changes in apical dendritic spine density have been observed in developing male mice during puberty and with castration (Meyer et al., 1978). The extent to which similar changes occur in female rats during development and puberty remains to be determined. Although the functional implications of these morphologic changes are unknown as of yet, variation in dendritic spine morphology has been suggested to modulate hippocampal physiology and to thereby be involved in memory formation (see above). Thus, it is possible that variations in the levels of steroid hormones, either long- or short-term, that mediate plasticity in the density of hippocampal dendritic spines could have important consequences for the processes of learning and memory and/or other behavioral endpoints of hippocampal function.

\section{References}

Bliss TVP, Lomo T (1973) Long-lasting potentiation of synaptic transmission in the dentate area of the anaesthetized rabbit following stimulation of the perforant path. J Physiol (Lond) 232:331-356.

Bradley P, Horn G (1979) Neuronal plasticity in the chick brain: morphological effects of visual experience on neurones in the hyperstriatum accessorium. Brain Res 162:148-153.

Brandon JG, Coss RG (1982) Rapid dendritic spine shortening during one-trial learning: the honeybee's first orientation flight. Brain Res 252:51-61.

Brown MW, Horn G (1979) Neuronal plasticity in the chick brain: electrophysiological effects of visual experience on hyperstriatal ncurones. Brain Res 162:142-147.

Burgess JW, Coss RG (1983) Rapid effect of biologically relevant stimulation on tectal neurons: changes in dendritic spine morphology after nine minutes are retained for twenty-four hours. Brain Res 266: 217-223.

Chang F-L, Greenough WT (1984) Transient and enduring morphological correlates of synaptic activity and efficacy change in the rat hippocampal slice. Brain Res 309:35-46.

Coss RG, Perkel DH (1985) The function of dendritic spines: a review of theoretical issues. Behav Neural Biol 44:151-185.

Crick F (1982) Do dendritic spines twitch? Trends Neurosci 5:44-46.

Desmond NL, Levy WB (1983) Synaptic correlates of associative potentiation/depression: an ultrastructural study in the hippocampus. Brain Res 265:21-30.

Desmond NL, Levy WB (1988) Anatomy of associative long-term synaptic modification. Neurol Neurobiol 35:201-204.

DeVoogd T, Nottebohm F (1981) Gonadal hormones induce dendritic growth in the adult avian brain. Science 214:202-204.

Diamond J, Gray EG, Yasaril GM (1970) The function of dendritic spines: an hypothesis. In: Excitatory synaptic mechanisms (Andersen P, Jansen J, eds), pp 213-222. Oslo: Universites Forlaget.

Diamond DM, Benett MC, Engstrom DA, Flesher M, Rose GM (1989) Adrenalectomy reduces the threshold for hippocampal primed burst potentiation in the anesthetized rat. Brain Res 492:356-360.

Enoka RM, Stuart DG (1984) Henneman's "size principle" current issues. Trends Neurosci 7:226-228.

Fifkova E, Van Harreveld A (1977) Long-lasting morphologic changes in dendritic spines of dentate granular cells following stimulation of the entorhinal area. $J$ Neurocytol 6:211-230.

Forger NG, Breedlove SM (1987) Seasonal variation in mammalian striated muscle mass and motoneuron morphology. J Neurobiol 18: 155-165.

Gabbott PL, Somogyi J (1984) The 'single' section Golgi impregnation procedure: methodological description. J Neurosci Meth 11:221-230.

Gould E, Woolley CS, Frankfurt M, McEwen BS (1990) Gonadal steroids regulate dendritic spine density in hippocampal pyramidal cells in adulthood. J Neurosci 10:1286-1291.

Greenough WT (1984) Structural correlates of information storage in the mammalian brain: a review and hypothesis. Trends Neurosci 7: $857-872$.

Greenough, WT (1985) The possible role of experience dependent 
synaptogencsis, or synapses on demand, in the memory process. In: Memory systems of the brain: animal and human cognitive processes (Weinberger NM, McGaugh JL, Lynch G, eds), pp 77-103. New York: Guilford.

Harris KM, Stevens JK (1989) Dendritic spines of CA1 pyramidal cells in the rat hippocampus: serial electron microscopy with reference to their biophysical characteristics. J Neurosci 9:2982-2997.

Kawakami M, Terasawa E, Ibuki T (1970) Changes in multiple unit activity in the brain during the estrous cycle. Neuroendocrinology 6 : $30-48$.

Kawato M, Hamaguchi T, Murakami F, Tsukahara N (1984) Quantitative analysis of the electrical properties of dendritic spines. Biol Cybern 50:447-454.

Kurz EM, Sengelaub DR, Arnold AP (1986) Androgens regulate dendritic length of sexually dimorphic mammalian motor neurons in adulthood. Science 232:395-398.

Loy R, Gerlach JL, McEwen BS (1988) Autoradiographic localization of estradiol-binding neurons in the rat hippocampal formation and entorhinal cortex. Dev Brain Res 39:245-251.

Lux HD, Schubert P, Kreutzberg GW (1970) Direct matching of morphological and electrophysiological data in cat spinal motoneurons. In: Excitatory synaptic mechanisms (Andersen P, Jansen J, eds), pp 189-198. Oslo: Universites Forlaget.

Meyer G, Ferres-Torres R, Mas M (1978) The effects of puberty and castration on hippocampal dendritic spines of mice. Brain Res 155: $108-112$.

Olton DDS (1983) Memory functions and the hippocampus. In: The hippocampus (Seifert W, ed), pp 335-373. London: Academic.

Parsons B, Rainbow TC, MacLusky NJ, McEwen BS (1982) Progestin receptor levels in rat hypothalamic and limbic nuclei. J Neurosci 2: 1446-1452.

Purves D, Hadley RD, Voyvodic JT (1986) Dynamic changes in the dendritic geometry of individual neurons visualized over periods of up to three months in the superior cervical ganglion of living mice. J Neurosci 6:1051-1060.

Sakasi M, Arnold AP (1989) Androgenic regulation of motoneurona dendritic morphology in the adult rat. Soc Neurosci Abstr 15:579.

Seikevitz P (1985) The post synaptic density: a possible role in longlasting effects in the central nervous system. Proc Nat Acad Sci USA 82:3494-3498.

Smith MS, Freeman ME, Neill JD (1975) The control of progesterone secretion during the estrous cycle and early pseudopregnancy in the rat: prolactin, gonadotropin, and steroid levels associated with the rescue of the corpus luteum of pseudopregnancy. Endocrinology 96: 219-226.

Squire LR (1983) The hippocampus and the neuropsychology of memory. In: The hippocampus (Seifert W, ed), pp 491-511. London: Academic.

Steward O (1986) Lesion-induced synapse growth in the hippocampus: in search of cellular and molecular mechanisms. In: The hippocampus Vol 3 (Isaacson RL, Pribrum KH, eds), pp 65-109. New York: Plenum.

Terasawa E, Timiras PS (1968) Electrical activity during the estrous cycle of the rat: cyclic changes in limbic structures. Endocrinology $83: 207-216$.

Turner CD, Bagnara JT (1976) The endocrinology of the ovary. In: General Endocrinology, 6th ed, pp 450-495. Philadelphia: Saunders.

Westrum LE, Blackstad TW (1962) An electron microscopic study of the stratum radiatum of the rat hippocampus (regio superior, CA1) with particular emphasis on synaptology. J Comp Neurol 119:281309.

Wilson CJ (1984) Passive cable properties of dendritic spines and spiny neurons. J Neurosci 4:281-297.

Woolley CS, McEwen BS (1990) Estradiol regulates synapse density in the CA1 region of the hippocampus in the adult female rat. Soc Neurosci Abstr 16:328. 